\title{
OPPORTUNITY FOR HEALTHY AGEING: LESSENING THE BURDEN OF ADULT PNEUMOCOCCAL DISEASE IN CENTRAL AND EASTERN EUROPE, AND ISRAEL
}

\author{
REVIEW AND ANALYSIS OF THE PROBLEM \\ Endre Ludwig', Serhat Ünal', Miron Bogdan ${ }^{3}$, Roman Chlibek, Yavor Ivanov ${ }^{5}$, Roman Kozlov ${ }^{6}$, Mark van der \\ Linden ${ }^{7}$, Hartmut Lode ${ }^{8}$, Zsófia Mészner ${ }^{9}$, Roman Prymula ${ }^{10}$, Galia Rahav ${ }^{11}$, Anna Skoczynska $^{12}$, Ivan Solovic ${ }^{13}$, \\ Esra Uzaslan ${ }^{14}$ \\ 'Division of Infectious Diseases, Department of Internal Medicine No. II, Semmelweis Medical University, Budapest, Hungary \\ ${ }^{2}$ Department of Internal Medicine, Hacettepe University Faculty of Medicine, Section of Infectious Diseases, Ankara, Turkey \\ ${ }^{3}$ Carol Davila University of Medicine, Bucharest and Marius Nasta Institute of Pneumophthisiology, Bucharest, Romania \\ ${ }^{4}$ Department of Epidemiology, Faculty of Military Health Sciences, University of Defence, Hradec Králové, Czech Republic \\ ${ }^{5}$ Pulmonology and Phthisiatry Clinic, University Hospital, Pleven, Bulgaria \\ ${ }^{6}$ Institute of Antimicrobial Chemotherapy, Smolensk State Medical Academy, Smolensk, Russia \\ ${ }^{7}$ German National Reference Center for Streptococci, Department of Medical Microbiology, University Hospital RWTH Aachen, Aachen, Germany \\ ${ }^{8}$ Research Center of Medical Studies (RCMS), Institut für Klinische Pharmakologie, Charite Universitätsmedizin Berlin, Germany \\ ${ }^{9}$ National Institute of Child Health, Szent Laszlo Hospital for Infectious Diseases, Budapest, Hungary \\ ${ }^{10}$ University Hospital, Hradec Králové, Czech Republic \\ ${ }^{11}$ Infectious Disease Unit, Sheba Medical Centre, Tel Hashomer, Ramat-Gan, Israel \\ ${ }^{12}$ National Reference Centre for Bacterial Meningitis, Department of Epidemiology and Clinical Microbiology, National Medicines Institute, \\ Warsaw, Poland \\ ${ }^{13}$ Pulmonology Department in National Institute for TB, Lung Diseases and Thoracic Surgery, Vyšné Hágy, Catholic University in Ružomberok, \\ Slovakia \\ ${ }^{14}$ Department of Pulmonology, Uludag University Faculty of Medicine, Bursa, Turkey
}

\section{SUMMARY}

The population of the Region (Central Europe, Eastern Europe, and Israel) is ageing, necessitating preventative programmes to maintain a healthy and active lifestyle in older age groups. Invasive pneumococcal disease (including bacteremic pneumonia, bacteremia without a focus, and meningitis) has higher incidence, morbidity and mortality in older adults and is a substantial public health burden in the ageing population.

Surveillance in the Region establishes a significant burden in older adults of invasive pneumococcal disease (IPD), which still appears to be under-estimated as compared with other countries, and this warrants an improvement in surveillance systems. The largest proportion of IPD in adults is bacteremic pneumonia. Community-acquired pneumonia (CAP), largely attributable to S. pneumoniae, can be bacteremic or non-bacteremic; the non-bacteremic forms of CAP also represent a significant burden in the Region.

The burden of pneumococcal disease can be reduced with programmes of effective vaccination. Recommendations on pneumococcal vaccination in adults vary widely across the Region. The main barrier to implementation of vaccination programmes is low awareness among healthcare professionals on serious heatlh consequences of adult pneumococcal disease and of vaccination options.

The Expert Panel calls on healthcare providers in the Region to improve pneumococcal surveillance, optimize and disseminate recommendations for adult vaccination, and support awareness and education programmes about adult pneumococcal disease.

Key words: invasive pneumococcal disease (IPD), community-acquired pneumonia (CAP), Central and Eastern Europe (CEE), Israel, pneumococcal vaccines, vaccination, elderly adults

Address for correspondence: E. Ludwig, Division of Infectious Diseases, Department of Internal Medicine No. II, Semmelweis Medical University, 1097 Gyáli ut 5-7. Budapest, Hungary. E-mail: eludwig@laszlokorhaz.hu

\section{Healthy Ageing: a Growing Public Health Issue \\ The proportion of adults in the Region (Central Europe, Eastern \\ Europe, and Israel) over the age of 50 years has nearly doubled}

in the past six decades (Fig. 1) and is forecasted to double again by 2040 (1). As a consequence, the Region will increasingly face the issue of "healthy ageing" (i.e. maintaining the general level of health, quality of life and active lifestyle in an ageing population). 


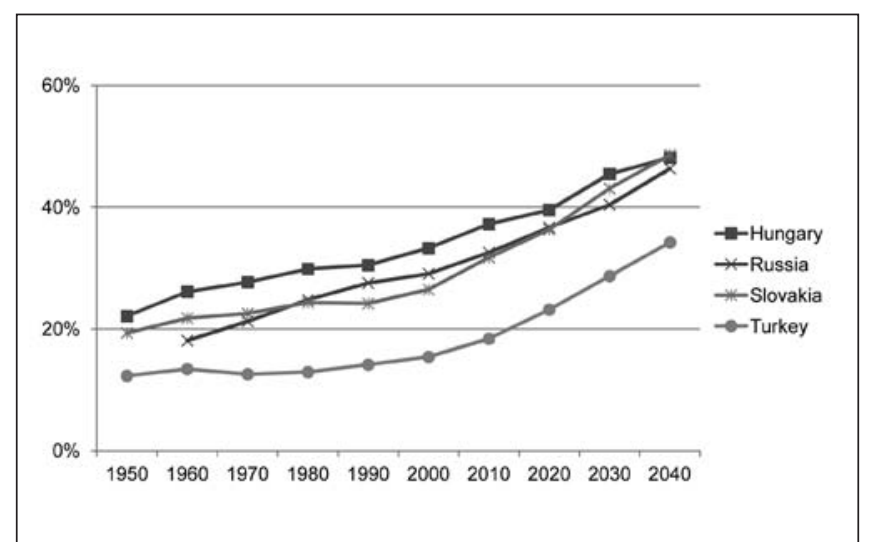

Fig. 1. Proportion of population over 50 years of age is growing in the countries of the Region. National census data from 1950 to 2000 (Hungary (43, 44), Turkey (45)) or 2010 (Russia (46), Slovakia (47)). Country forecast through 2040 by US Census Bureau (44).

Public health should target preventable diseases associated with older age and related co-morbidities (2) by programmes ranging from already established initiatives for reduction of cardiovascular risks to currently less utilized options for adult vaccination.

\section{Adult Vaccination - the Neglected Solution?}

The public health value of prevention through vaccination (i.e. lowering disease incidence in the target population) is well documented in paediatric populations and likewise in adults. The value can expand beyond direct effects like an impact on the incidence of invasive pneumococcal disease (IPD) cases in the target population. For instance, successful pneumococcal vaccination in paediatric programmes has associated individual and economic benefits, such as an impact on the patterns of antibiotic therapy, thus reducing the number of treatment failures linked to antibiotic resistance (3). In adults, pneumococcal vaccination, in addition to its protective effect against pneumococcal disease, may prevent pneumonia-associated cardiovascular events (4) and, when co-administered with influenza vaccina- tion, may reduce the risk of myocardial infarction and stroke in the elderly (5).

However, the preventative value of vaccination in adults is under-recognised. Healthcare providers traditionally associate vaccination programmes with paediatric practice. "Vaccination for kids" is the current paradigm that needs to be transformed to address the substantial but not fully appreciated public health needs of the ageing population. Preventive potential of adult pneumococcal vaccination is particularly neglected in the Region, due to low awareness of the burden of pneumococcal disease in adults and under-recognition of the potential of preventive measures (6).

\section{Pneumococcal Disease: a Major Preventable Health Burden}

S. pneumoniae causes invasive and non-invasive pneumococcal diseases. IPD includes bacteremic pneumonia, bacteremia without a focus, and meningitis. The majority of IPD cases in adults presents as bacteremic pneumonia (7-11). The incidence, morbidity and mortality of IPD are especially elevated in older adults and present a significant burden to individuals and to society (Fig. 2). Among the other risk factors for pneumococcal disease such as co-morbidities, residence in a long-term care facility or smoking, age is an independent risk factor. The most prevalent form of pneumococcal disease in older adults is community-acquired pneumonia (CAP), which presents a substantial clinical and economic burden (12-15). Moreover, S. pneumoniae is a major contributor to exacerbations of COPD (16), the disease burden in the Region is at least comparable to, and may even exceed, that of CAP $(13,17)$. Therefore, the burden of pneumococcal disease in adults is immense.

\section{The Burden of IPD - How Much Remains Hidden?}

Diagnosis of IPD (via positive blood or cerebrospinal fluid culture) requires laboratory analysis that cannot be established without adequate infrastructure and resources. Therefore, reliable epidemiological data on IPD depend on the quality of surveillance systems and in particular on collaboration between laboratory and clinical facilities. Diverse surveillance systems in many countries

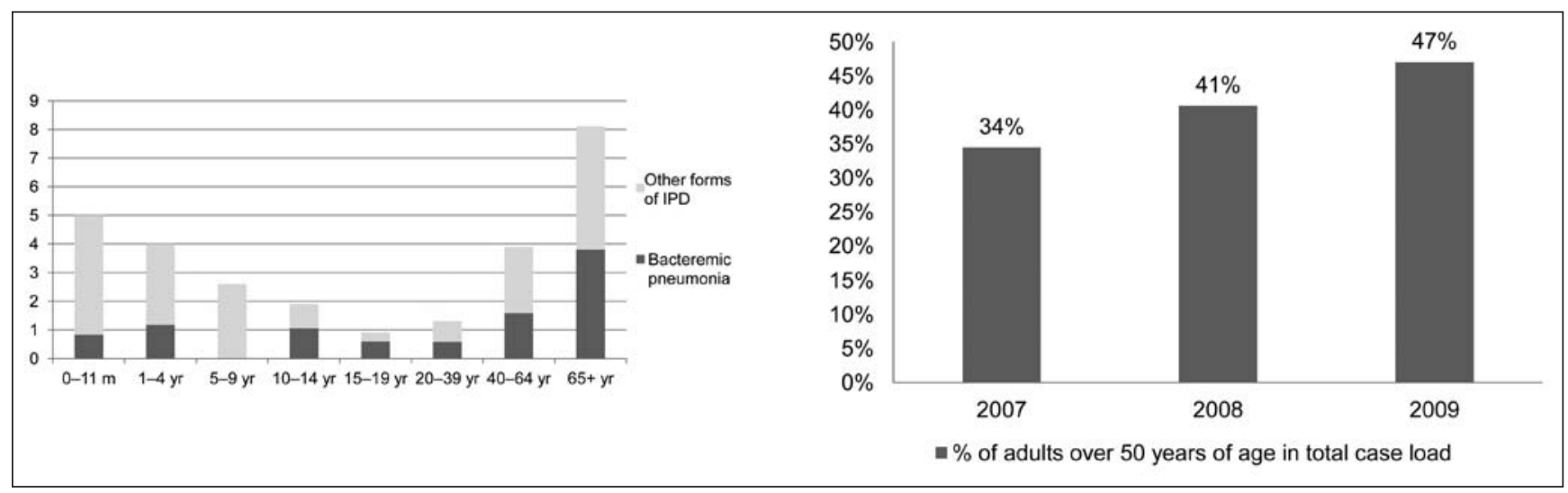

Fig. 2. Older adults have a high incidence of IPD and represent a growing share of national IPD burden. Left panel: IPD incidence (per 100,000) by age group, Czech Republic, 2009 (10). Right panel: Share of adults over 50 (\%) in IPD case load, Poland, 2007-2009 (11). 
of the Region merit improvement (18); in particular, systems of active surveillance are under-represented. In many cases, blood culture is not performed at all, or performed at later stage, or the results are not reported correctly. Furthermore, national compulsory surveillance for IPD does not exist in several countries. A specific issue in the Region is the lack of continuity in the funding of such systems. Surveillance systems in some countries, such as Poland and the Czech Republic, have recently been improved, and in 2009 the reported figures for the burden of IPD in adults in these countries were greater than in previous years, possibly due to these improvements $(10,11)$ (Fig. 2). The largest age-specific IPD mortality rate values were 44\% (55-64 years) and 59\% (65+ years) in Poland $(10,11)$. In the Czech Republic, the $65+$ years age group had the greatest age-related IPD incidence of 8.8 per 100,000 population per year (and it was 3.3 per 100,000 for age group 40-64 years) (10). By contrast, these reported IPD incidence rates are substantially lower than the 51.9 and 18.1 per 100,000 in the same age groups in Israel for pneumococcal bacteremia (9). Comparisons with current data from other European countries also suggest that IPD may still be dramatically under-reported in the Region, especially in adults in the 50+ years age group (19). Publications from the Region also report a significant burden of adult IPD in terms of healthcare costs and resource utilization $(15,20,21)$.

\section{The Burden of CAP - Are Antibiotics an Easy Cure?}

A significant proportion of CAP is attributable to S. pneumoniae. In multiple European studies investigating the aetiology of CAP, S. pneumoniae was the most frequently identified pathogen $(12,22)$ regardless of age group, clinical severity or country. $S$. pneumoniae is also the most frequently identified cause of bacteremia in CAP (23). Aetiological verification of CAP and detection of bacteremia in clinical practice may be challenging because of initiation of antibiotic therapy before obtaining cultures, and cultures are often not performed due to limited practice of collecting bacteriological material in hospital settings and/or limited laboratory capacity. Given the current reliance on clinical examination and X-ray diagnosis in CAP, there may be insufficient recognition that this disease is predominantly caused by the pneumococcus. This may be especially true in primary care, where a vast majority of CAP patients receive empiric antibacterial therapy.

Improvement of diagnostic and treatment pathways alone, without a clear preventative strategy, may not be sufficient to adequately control the burden of CAP. Rates of CAP hospitalization and CAP mortality remain especially high in older patients in spite of apparent advances in therapy. According to a German nationwide hospital audit, hospital mortality in CAP significantly increases from the age of 40 years and hospitalization rates significantly increase from the age of 50 years (24). Early recognition and adequate antibiotic therapy in the first hours after admission improve the outcomes of hospitalization in both bacteremic and non-bacteremic CAP $(25,26)$, although antibiotic resistance of $S$. pneumoniae may lead to some treatment failures (12). Moreover, hospital mortality is especially high in the first 4 days after admission, which may be explained by the fact that pneumonia is a severe inflammatory illness, with the gravity of disease compounded by delayed referral of (potentially severe) cases by primary care physicians (PCPs) and/or delayed initiation of antibacterial treatment.
Bacteremia in pneumococcal CAP is more frequent in older adults and may be a risk factor for greater likelihood of severity and mortality $(27,28)$. Referral decisions can be ameliorated by the application of validated risk scales, such as CRB65 (Severity score for CAP based on: Confusion, Respiratory rate, Blood pressure, and 65 years of age and older) (25). Furthermore, the burden of CAP remains profound even after recovery and discharge from the hospital (24-32). Symptoms can take weeks to resolve (29), and a substantial proportion of patients hospitalized with CAP require re-hospitalization within 30 days (30). Of even more concern is long-term mortality, which remains significantly higher than in the general population for several years after the initial episode, especially in CAP caused by $S$. pneumoniae $(31,32)$.

\section{Pneumococcal Vaccinations in Adults: Recommenda- tions vs. Implementation}

Recommendations for pneumococcal vaccination in adults exist in most countries of the Region and predominantly call for a single dose of plain polysaccharide vaccine in adults older than 65 years of age (33) or in younger adults with well-established risk factors. At the same time, the actual uptake of pneumococcal vaccination in adults has been negligible (34). Consequently, the content of national recommendations from different bodies needs to be accurate, uniform, simple and practical. More importantly, their implementation needs to be addressed to improve the impact of adult pneumococcal vaccination.

\section{Considerations for Vaccination Recommendations}

IPD and CAP represent a significant preventable burden in adults from the age of 50 years. With increasing life expectancy, vaccination recommendations should address the extended period of risk. A primary dose of vaccine, followed by the ability to maintain a protective immune response through regular re-vaccination as needed, may provide continued protection even in the face of the immunosenescence associated with aging. Polysaccharide vaccines have shown a certain level of effectiveness against invasive pneumococcal disease but evidence of their effectiveness in all-cause pneumonia is inconsistent. Furthermore, polysaccharide vaccines have a number of limitations with regard to the immune responses in older age groups (35): protection provided by a dose of plain polysaccharide vaccine wanes over time, and re-vaccination is currently not recommended as the benefit is doubtful (36-38). Protection is also less likely to be demonstrated in more elderly age groups or in immuno-compromised individuals $(39,40)$. Consequently, pneumococcal vaccines are needed that are capable of establishing immune memory initially and that retain the potential for an individual to be re-vaccinated as necessary throughout the aging adult risk period.

\section{Overcoming Barriers to Successful Implementation}

A number of barriers hinder the successful implementation of vaccination recommendations in adults (41). Patient barriers include general low health awareness and poor knowledge of the safety and benefits of vaccination in adults. A major barrier for potential vaccine recipients is missing opportunities to have vaccination recommended and administered during their encoun- 
ters with healthcare professionals (42), who in-turn may have an incomplete understanding of the seriousness of pneumococcal disease (6). Additional barriers specific to the Region are: inconsistent reimbursement policies in several countries and associated low public compliance to carry out-of-pocket expenses; variability in the age and risk groups for which vaccination is recommended; a negative attitude of the media towards vaccination in general.

For pneumococcal disease in adults, PCPs may play a key part in prevention, diagnosis and referral, especially in those healthcare systems where they play a gatekeeper role. Continual changes in healthcare systems overwhelm PCPs with multiple complex procedures and guidelines, which are often poorly implemented. A key success factor is therefore the implementation of clear and easy-to-follow recommendations and tools to motivate PCPs to vaccinate adults. Other stakeholders such as policy makers, payers, media and the public have low awareness of, and commitment to vaccination in adults. There are even examples of anti-vaccination attitudes among the public and the media. However, the attitude of non-medical audiences is unlikely to change before healthcare professionals manifest improved awareness of, and commitment to pneumococcal vaccination of adults.

\section{Conclusions: Call to Action}

The Expert Panel calls on healthcare providers and policy makers in the Region to lessen the burden of pneumococcal disease in adults and to make a concerted effort to address the unmet needs.
- Educational programmes with clear messages and usable tools should be addressed in a top-down approach to multiple audiences including PCPs and allied healthcare professionals.

\section{Acknowledgements}

Editorial assistance for the manuscript was provided by Dr. Dmitry Nonikov, Edelman, London, and funded by Pfizer Inc.

\section{Conflicts of interest}

Endre Ludwig: Financial support for participating and working as consultant in advisory boards by Astellas, MSD; Honoraria as speakers in scientific meetings by Bayer

Roman Chlibek: Principal investigator in clinical studies supported by GlaxoSmithKline and Novartis; Scientific consultant to Baxter, GlaxoSmithKline, Novartis, Aventis Pasteur and Pfizer; Sponsorship from GlaxoSmithKline and Aventis Pasteur to attend scientific meetings.

Mark van der Linden: Member of advisory boards for Pfizer, GlaxoSmithKline and Sanofi, invited speaker for Pfizer and GSK

Zsofia Meszner: Financial support for participating and working as consultant in advisory boards by Pfizer, GSK and Sanofi

Roman Prymula: Received honoraria and research grants form GSK, Pfizer, and Sanofi-Pasteur

Anna Skoczynska: Assistance to attend scientific meetings; honoraria for lecturing funded from Pfizer/Wyeth and from GlaxoSmithKline

\section{Sponsorship}

Financial support for the Regional Advisory Board on Pneumococcal Diseases in Adults was provided by Pfizer, Inc.

\section{Optimised Surveillance Systems and Epidemiology Studies}

- Require regional protocols and/or data centres that are optimised to generate consistent and comparable epidemiology data on adult pneumococcal disease (e.g. IPD and CAP).

- Perform sentinel studies in selected locations that may be instrumental in establishing the actual incidence, morbidity and mortality of IPD and CAP.

\section{State-of-the-art Vaccination Recommendations}

- IPD and CAP represent significant risks and a preventable burden for adults starting at 50 years of age.

- There is a rationale for immunisation throughout the adult risk period that involves priming by a pneumococcal vaccine that provides a protective immune response, followed by the possibility of regular re-vaccination, if necessary, to provide continued protection, even in the face of any immunosenescence associated with aging.

\section{Coordinated Awareness and Implementation Efforts}

- Data on the pneumococcal disease burden and information about successful vaccination programmes should be communicated beyond the specialist community to healthcare professionals, the public and policy makers.

- Public health policy and reimbursement decisions need to be made to allocate sufficient resources for the prevention of pneumococcal disease in adults.

\section{REFERENCES}

1. Kinsella K, He W. International population reports: an ageing world 2008. P95/09-1. Washington, DC: US Government Printing Office; 2009.

2. Plotkin SL, Plotkin SA. A short history of vaccination. In: Plotkin SA, Orenstein WA, editors. Vaccines. 4th ed. Philadelphia: WB Saunders; 2004. p. 1-15.

3. Kyaw MH, Lynfield R, Schaffner W, Craig AS, Hadler J, Reingold A, et al.; Active Bacterial Core Surveillance of the Emerging Infections Program Network. Effect of introduction of the pneumococcal conjugate vaccine on drug-resistant Streptococcus pneumoniae. N Engl J Med. 2006 Apr 6;354(14):1455-63. Erratum in: N Engl J Med. 2006 Aug 10;355(6):638.

4. Madjid M. Acute infections, vaccination and prevention of cardiovascular disease. CMAJ. 2008 Oct 7;179(8):749-50.

5. Hung IF, Leung AY, Chu DW, Leung D, Cheung T, Chan CK, et al. Prevention of acute myocardial infarction and stroke among elderly persons by dual pneumococcal and influenza vaccination: a prospective cohort study. Clin Infect Dis. 2010 Nov 1;51(9):1007-16.

6. Madar R, Strakova J, Baska T, Kavcova E, Straka S. Pneumococcal vaccination - current situation and perspectives. Bratisl Lek Listy. 2005;106(3):119-22.

7. Robinson KA, Baughman W, Rothrock G, Barrett NL, Pass M, Lexau C, et al.; Active Bacterial Core Surveillance (ABCs)/Emerging Infections Program Network. Epidemiology of invasive Streptococcus pneumoniae infections in the United States, 1995-1998: Opportunities for prevention in the conjugate vaccine era. JAMA. 2001 Apr 4;285(13):1729-35.

8. Kyaw MH, Clarke S, Jones IG, Campbell H. Incidence of invasive pneumococcal disease in Scotland, 1988-99. Epidemiol Infect. 2002 Apr;128(2):139-47.

9. Raz R, Elhanan G, Shimoni Z, Kitzes R, Rudnicki C, Igra Y, et al.; Israeli Adult Pneumococcal Bacteremia Group. Pneumococcal bacteremia in hospitalized Israeli adults: epidemiology and resistance to penicillin. Clin Infect Dis. 1997 Jun;24(6):1164-8. 
10. Motlová J, Kozáková J, Kř́̌žová P. Invasive pneumococcal disease in the Czech Republic in 2010. Zpr Epidemiol Mikrobiol. 2011;20(2):64-9. (In Czech.)

11. Skoczyńska A, Sadowy E, Bojarska K, Strzelecki J, Kuch A, Gołębiewska A, et al.; Participants of laboratory-based surveillance of community acquired invasive bacterial infections (BINet). The current status of invasive pneumococcal disease in Poland. Vaccine. 2011 Mar 3;29(11):2199-205.

12. Welte T, Torres A, Nathwani D. Clinical and economic burden of community-acquired pneumonia among adults in Europe. Thorax. 2012 Jan;67(1):71-9.

13. European Lung Foundation (ELF). Lung health in Europe - facts and figures [Internet]. Sheffield: ELF; 2003 [cited 2010 June 20]. Available from: http://www.european-lung-foundation.org/8-contact.htm.

14. Doruk S, Tertemiz KC, Kömüs N, Uçan ES, Kilinç O, Sevinç C. Community acquired pneumonia and direct hospital cost. Tuberk Toraks. 2009;57(1):48-55

15. Jahnz-Rózyk K. Health economic impact of viral respiratory infections and pneumonia diseases on the elderly population in Poland. Pol Merkur Lekarski. 2010 Jul;29(169):37-40. (In Polish.)

16. Schenkein JG, Nahm MH, Dransfield MT. Pneumococcal vaccination for patients with COPD: current practice and future directions. Chest. 2008 Mar;133(3):767-74

17. Jahnz-Rózyk K, Targowski T, From S. Comparison of outpatient and inpatient costs of moderate and severe exacerbations of chronic obstructive pulmonary disease in Poland. Pneumonol Alergol Pol. 2008;76(6):426-31. (In Polish.)

18. Hanquet G, Perrocheau A, Kissling E, Bruhl DL, Tarragó D, Stuart J, et al.; ECDC Country Experts for Pneumococcal Disease. Surveillance of invasive pneumococcal disease in 30 EU countries: Towards a European system? Vaccine. 2010 May 21;28(23):3920-8

19. European Centre for Disease Prevention and Control (ECDC). Annual epidemiological report on communicable diseases 2009 [Internet]. Stockholm: ECDS; 2010 [cited 2010 June 20]; p. 166-67. Available from: http://www.ecdc.europa.eu/en/publications/surveillance reports/ annual_epidemiological_report/Pages/epi_index.aspx.

20. Madar R, Malechova L, Baska T. Pneumococcal meningitis - comparison of therapy and vaccination costs. Bratisl Lek Listy. 2008;109(3):130-2.

21. Akin L, Kaya M, Altinel S, Durand L. Cost of pneumococcal infections and cost-effectiveness analysis of pneumococcal vaccination at risk adults and elderly in Turkey. Hum Vaccin. 2011 Apr;7(4):441-50.

22. Köksal I, Ozlü T, Bayraktar O, Yılmaz G, Bülbül Y, Oztuna F, et al.; TU CAP Study Group. Etiological agents of community-acquired pneumonia in adult patients in Turkey; a multicentric, cross-sectional study. Tuberk Toraks. 2010;58(2):119-27.

23. Bishara J, Leibovici L, Ashkenazi S, Samra Z, Pitlik S. Seven-year study of bacteraemic pneumonia in a single institution. Eur J Clin Microbiol Infect Dis. 2000 Dec;19(12):926-31.

24. Ewig S, Birkner N, Strauss R, Schaefer E, Pauletzki J, Bischoff H, et al. New perspectives on community-acquired pneumonia in 388406 patients. Results from a nationwide mandatory performance measurement programme in healthcare quality. Thorax. 2009 Dec;64(12):1062-9

25. Garnacho-Montero J, García-Cabrera E, Diaz-Martín A, Lepe-Jiménez JA, Iraurgi-Arcarazo P, Jiménez-Alvarez R, et al. Determinants of outcome in patients with bacteraemic pneumococcal pneumonia: importance of early adequate treatment. Scand J Infect Dis. 2010 Mar;42(3):185-92.

26. Berjohn CM, Fishman NO, Joffe MM, Edelstein PH, Metlay JP. Treatment and outcomes for patients with bacteremic pneumococcal pneumonia. Medicine (Baltimore). 2008 May;87(3):160-6.

27. Lin SH, Lai CC, Tan CK, Liao WH, Hsueh PR. Outcomes of hospitalized patients with bacteraemic and non-bacteraemic community-acquired pneumonia caused by Streptococcus pneumoniae. Epidemiol Infect. 2011 Sep;139(9):1307-16.

28. Ewig S, Torres A. Severe community-acquired pneumonia. Clin Chest Med. 1999 Sep;20(3):575-87.

29. Metlay JP, Atlas SJ, Borowsky LH, Singer DE. Time course of symptom resolution in patients with community-acquired pneumonia. Respir Med. 1998 Sep;92(9):1137-42.
30. Jasti H, Mortensen EM, Obrosky DS, Kapoor WN, Fine MJ. Causes and risk factors for rehospitalization of patients hospitalized with communityacquired pneumonia. Clin Infect Dis. 2008 Feb 15;46(4):550-6.

31. Koivula I, Stén M, Mäkelä PH. Prognosis after community-acquired pneumonia in the elderly: a population-based 12-year follow-up study. Arch Intern Med. 1999 Jul 26;159(14):1550-5.

32. Bordon J, Wiemken T, Peyrani P, Paz ML, Gnoni M, Cabral P, et al.; CAPO Study Group. Decrease in long-term survival for hospitalized patients with community-acquired pneumonia. Chest. $2010 \mathrm{Aug}$;138(2):279-83.

33. Muchl R, Van Damme P, Kojouharova M, Kriz B, Hadjianatassiou C, Glismann S, et al. Report on the first survey of immunisation programs in Europe: VENICE Project [Internet]. 2007 [cited 2011 Jun 8]. Available from: http://venice.cineca.org/Report II WP3.pdf.

34. TIHUD. Immunization in the elderly. Report of EGE Working Group of the Turkish Society of Internal Medicine [Internet]. Ankara; 2010 [cited 2011 Jun 8]. Available from: http://www.tihud.org.tr/main/ renderFile?id=97. (In Turkish.)

35. Harrison LH. Prospects for vaccine prevention of meningococcal infection. Clin Microbiol Rev. 2006 Jan;19(1):142-64.

36. Mandell LA, Wunderink RG, Anzueto A, Bartlett JG, Campbell GD, Dean $\mathrm{NC}$, et al.; Infectious Diseases Society of America; American Thoracic Society. Infectious Diseases Society of America/American Thoracic Society consensus guidelines on the management of community-acquired pneumonia in adults. Clin Infect Dis. 2007 Mar 1;44 Suppl 2:S27-72.

37. Woodhead M, Blasi F, Ewig S, Huchon G, Ieven M, Ortqvist A, et al.; European Respiratory Society; European Society of Clinical Microbiology and Infectious Diseases. Guidelines for the management of adult lower respiratory tract infections. Eur Respir J. 2005 Dec;26(6):1138-80. Review. Erratum in: Eur Respir J. 2006 Feb;27(2):439.

38. Lim WS, Baudouin SV, George RC, Hill AT, Jamieson C, Le Jeune I, et al; Pneumonia Guidelines Committee of the BTS Standards of Care Committee. BTS guidelines for the management of community acquired pneumonia in adults: update 2009. Thorax. 2009 Oct;64 Suppl 3:47-55.

39. Siegrist CA, Aspinall R. B-cell responses to vaccination at the extremes of age. Nat Rev Immunol. 2009 Mar;9(3):185-94

40. Lang PO, Govind S, Michel JP, Aspinall R, Mitchell WA. Immunosenescence: Implications for vaccination programmes in adults. Maturitas. 2011 Apr;68(4):322-30.

41. Blank PR, Schwenkglenks M, Szucs TD. Disparities in influenza vaccination coverage rates by target group in five European countries: trends over seven consecutive seasons. Infection. 2009 Oct;37(5):390-400.

42. Mieczkowski TA, Wilson SA. Adult pneumococcal vaccination: a review of physician and patient barriers. Vaccine. 2002 Jan 31;20(9-10):1383-92.

43. Hungarian Central Statistical Office (KSH). Population by age groups and sex 1870 - 2005 [Internet]. 2006 [cited 2011 Jun 8]. Available from: http:// www.mikrocenzus.hu/mc2005_eng/volumes/02/tables/load1_1_5_1. html.

44. US Census Bureau. International Data Base [Internet]. US Census Bureau; 2011 [cited 2011 June 8]. Available from: http://www.census.gov/ population/international/data/idb/informationGateway.php.

45. Turkish Statistical Insitute (TurkStat). Statistical indicators 1923-2010 [Internet]. 2011 [cited 2011 Oct 21]. Available from: http://www.turkstat. gov.tr/Kitap.do?metod=KitapDetay\&KT_ID $=0 \&$ KITAP_ID $=158$. (In Turkish.)

46. Russian State Committee for Statistics (GKS). The Russian demographic year book [Internet]. 2010 [cited 2012 May 21]. Available from: http:// www.gks.ru/wps/wcm/connect/rosstat/rosstatsite/main/publishing/cata$\log /$ statisticCollections/doc_1137674209312. (In Russian.)

47. Statistical Office of the Slovak Republic (SOSR). Population age structure of the Slovak Republic in 2009 [Internet]. Bratislava: 2010 [cited 2010 Jun 21]. Available from: http://www.statistics.sk/pls/elisw/objekt. send?uic $=2477 \&$ m_sso $=2 \&$ m_so $=7 \& \mathrm{ic}=30$. (In Slovak.) 